\title{
Nickel Coatings Electrodeposited from Watts Type Baths Containing Quaternary Ammonium Sulphate Salts
}

\author{
Jarosław Wojciechowski ${ }^{1}$, Marek Baraniak ${ }^{1}$, Juliusz Pernak ${ }^{2}$, Grzegorz Lota ${ }^{1, *}$ \\ ${ }^{1}$ Poznan University of Technology, Institute of Chemistry and Technical Electrochemistry, \\ Berdychowo 4, 60-965 Poznan, Poland \\ ${ }^{2}$ Poznan University of Technology, Institute of Chemical Technology and Engineering, Berdychowo \\ 4, 60-965 Poznan, Poland \\ *E-mail: grzegorz.lota@ put.poznan.pl
}

doi: $10.20964 / 2017.04 .70$

Received: 5 January 2017 / Accepted: 23 February 2017 / Published: 12 March 2017

The paper presents the anti-corrosive properties of nickel coatings, deposited on the surface of the steel AISI 1018 from Watts type baths, containing protic and aprotic quaternary ammonium sulphate salts additives. Nickel electrodeposition was carried out using two different values of current density. Four different solutions contained protic and aprotic quaternary ammonium sulphate salts with a different number of carbon atoms in the alkyl chain. Scanning electron microscope and X-ray scattering methods were used to analyse the surface of obtained coatings. Anti-corrosive properties were determined by means of electrochemical impedance spectroscopy measurements. The results demonstrate a significant effect of current density values on the texture and thickness of the nickel coatings, and quaternary ammonium salts on their anti-corrosive properties. Samples containing aprotic salts with three $-\mathrm{CH}_{3}$ substituents and the carbon chain of 6 carbon atoms inhibit the corrosion process to the greatest extent.

Keywords: Corrosion protection, Electrochemical impedance spectroscopy, Nickel coating, Quaternary ammonium salt

\section{$\underline{\text { FULL TEXT }}$}

(C) 2017 The Authors. Published by ESG (www.electrochemsci.org). This article is an open access article distributed under the terms and conditions of the Creative Commons Attribution license (http://creativecommons.org/licenses/by/4.0/). 